\title{
Teatro e hip-hop: \\ a experiência do Núcleo Bartolomeu de Depoimentos
}

\author{
Antônio Rogério Toscano
}

[...] Aquilo que na cultura hip-hop se chama atitude talvez seja a sintese de uma estética e de uma ética, que se combinam de modo muito próprio na construção da pessoa. ${ }^{1}$

ntes do teatro, o homem ("a pessoa"). Mais do que dramaturgia, depoimento. Estética e ética, amalgamadas, gritam, pela voz do ator- $M C$ que se apropria, com o impacto de um sampler teatral, do canto negro do rapper Rappin'Hood: "Se eu tô com o microfone, é tudo no meu nome!”. ${ }^{2}$

$\mathrm{Na}$ cultura de rua, arte é atitude. E precisa ter "proceder, tá ligado?"

A importância do hip-hop no contexto de formação de uma cultura popular urbana e sua posição estratégica no diálogo com jovens, via de regra meninos e meninas negros e pobres, moradores dos bolsões mais miseráveis da periferia das grandes cidades (mas também, hoje em dia, garotos e garotas de outras classes sociais, brancos ou mestiços, excluídos ou não, quando, como os primeiros, estão francamente interessados pela articulação de um discurso vivo e atuante - em geral, dito por manos focados na possibilidade de sua auto-representação em um mundo de idéias falidas), mostramnos como o contato com o rap e a resultante hibridização das formas convencionais de teatro têm coisas sérias a dizer para este "tempo que nos toca viver". 3

Marcada pela proposição da não-violência, a cultura de rua que gera o movimento

Antonio Rogério Toscano é dramaturgo, professor de Teoria do Teatro e coordenador da Escola Livre de Teatro de Santo André.

1 Soares; Bill \& Athayde, 2005, p. 206.

2 Hood, Rappin'. Sujeito homem (CD). Trama, 2001. [Este bordão do rapper paulistano Rappin'Hood, oriundo do coletivo Posse Mente Zulu, atravessa algumas faixas deste seu primeiro CD, em que se reiteram os comprometimentos éticos da criação e a afirmação da autoria do pensamento, necessários para escapar ao jugo das formas hegemônicas de desprezo à cultura negra. Em Sou negrão, o compromisso está em: "Não tenho toda malandragem de Bezerra da Silva / Nem o canto refinado de Paulinho da Viola / Sou só mais um neguinho pelas ruas da vida / Que quer se divertir, fazer um som e jogar bola I Rappin'Hood sou, hã, sujeito homem / Se eu tô com o microfone é tudo no meu nome”.]

3 Jargão da dramaturga Claudia Schapira, que costuma substituir com esta expressão a fala sobre sua contemporaneidade participante. 
hip-hop na década de 1970 é responsável pela mudança de paradigmas na consciência de jovens excluídos que passam a ver nas rimas, nos scratches e no break a possibilidade de amplificar sua visibilidade social - até então só possível com um berro na mão. ${ }^{4}$

No depoimento de Thaíde (ex-integrante da dupla Thaíde e DJ Hum, pioneira do hiphop no Brasil, desde as primeiras ocupações coletivas de espaços públicos, inspiradas pelas disco mobiles - discoteca móvel, festa de rua - e pelas block parties - festas de quarteirão -, no calçadão do metrô São Bento), a mudança de referencial do que deva ser o cidadão negro, em sua auto-imagem projetada pela poesia, é ponto fundamental para a sobrevivência de quem não deseja ser engolido pela hidra de muitas cabeças que é a violência, nas quebradas da cidade, na favela:

Quando eu cresci, quando comecei a me enxergar como adulto, eu comecei a tomar consciência da minha negritude. E isso só aconteceu através da cultura hip-hop. Eu já conseguia perceber isso nos bailes de soul e de funk. Mas foi o movimento hip-hop que realmente abriu a minha cabeça. Foi pelo movimento hip-hop que eu comecei a perceber que através da música nós poderíamos chegar muito longe. ${ }^{5}$

Para Maria Rita Kehl, "a música popular, no Brasil, é uma produção discursiva muito forte e presente; talvez a mais forte em um país marcado pelo analfabetismo. A música popular aqui assumiu esta função de produzir sentido para a vida em sociedade, para as nossas diferenças, para as misérias e riquezas humanas deste país" ${ }^{6}$

E, na crise social contemporânea, há uma invasão do espaço público (degradado pelo abandono dos poderes constituídos) na vida privada de quem vive nos becos menos favorecidos da cidade. Isso faz com que o sujeito musical "de nome próprio [aquele que depõe, se está com o microfone - do mangue beat, do rap e das demais formas sonoras vindas da miséria], que acolhe em seu eu os ecos da coletividade a que pertence" expanda sua qualidade autoral, e passe a cantar seus problemas em primeira pessoa, ${ }^{7}$ em oposição à condição crítica assumida pela $\mathrm{MPB}$, que enxerga e denuncia os problemas sociais do ponto de vista de quem assiste ao horror - e não o vive, na carne, diariamente.

$\mathrm{O}$ rap (rithym and poetry), aliado à sua roupagem característica, às posturas e aos comportamentos éticos, à dança de rua e à exposição visual do grafitte, alimenta no imaginário contemporâneo uma vivacidade crítica extremamente aguçada, que estimula o confronto com a baixa auto-estima histórica e a resistência através da vivência de um jogo criativo que burla o caos social e a invisibilidade simbólica de seus criadores frente ao establishment artístico e do mundo real; sobretudo, gera "sobreviventes no inferno" 8 da vida social.

É por isso que uma releitura brechtiana heterodoxa de um teatro popular atuante na sel-

4 Soares, 2004.

5 Alves, 2004.

6 Kehl, 2004.

7 Id., ibidem.

8 O CD Sobrevivendo no inferno [1998, independente], dos paulistanos Racionais MC's, é um marco histórico de articulação poética e política realizada de forma independente, sem o alicerce de grandes gravadoras, e que representa de modo contundente toda uma geração de jovens que se reconhece em seus discursos, em suas letras e em seus samplers. 
va das cidades, como é o do Núcleo Bartolomeu de Depoimentos (NBD), deseja fincar raízes no diálogo com a sensibilidade/atitude vinda das ruas, que são, para a dramaturga e encenadora Claudia Schapira, o verdadeiro espaço de troca de experiências vivas da atualidade:

[...] O teatro nasceu na rua, ela é ainda hoje uma ágora. Na rua, você tem a democracia mais plena. Tem ali uma questão de a gente conseguir quebrar todas as fronteiras, de estabelecer uma relação de igual pra igual com a pessoa que está lá para trocar com o artista. O público tem, porque lhe é devolvida, uma função no teatro.?

Mas, ao contrário do que este trecho, isoladamente, pode sugerir, não se trata, aqui, da formulação de uma poética de "teatro de rua". A atitude, vinda do repertório do hip-hop, é o que estimula a abertura de vínculos imediatos com a rua, seja em intervenções cênicas que podem ser praticadas em um contexto de ativismo poético, seja na forma de encarar a rua como um canal por onde escoa, sem mediaçôes, a inspiração que gera um espetáculo.

O Bartolomen - Que será que nele deu? surgiu, para mim, surgiu de eu ver as pessoas atravessarem a rua às seis horas da tarde. Em bloco. Eu achei aquilo uma coisa maravilhosa. Eu pensei: 'todo mundo anda junto, chega junto do outro lado, no mesmo ritmo...' É uma partitura urbana. Quando você reproduz isso em cena, você vai desenvolvendo várias maneiras de abordar criativamente esses blocos, um corpo, vários corpos... Existem várias maneiras de encontrar esses corpos coletivos, esses coletivos urbanos. $\mathrm{E}$ isso me faz entender que o corpo não é somente uma via de expressão, ele pode ter uma amplitude que alcança o discurso da cena - então ele pode se tornar dramaturgia. ${ }^{10}$

Aqui, a atitude tem parentesco com o gestus de Bertolt Brecht.

No NBD, que caminha para completar seus 7 anos de existência, desde a junção de artistas sob a batuta de Claudia Schapira para a montagem multimídia de Bartolomeu - Que será que nele deu?, em janeiro de 2000, além do contato íntimo com a atitude hip-hop, a característica mais importante reside no fato de que suas bases criativas não estão organizadas como as de um grupo de teatro tradicional.

Embora suas atividades artísticas sejam exemplares do que se tem chamado no teatro contemporâneo brasileiro de teatro de grupo (participação coletiva nas decisões; pesquisa continuada e coerência poética; comandos de produção divididos entre os participantes, com responsabilidades demarcadas; valorização dos processos criativos, mais do que de resultados espetaculares; dramaturgias próprias geradas em trabalhos cênicos horizontais, em que, em alguma medida, os diferentes modos de processos colaborativos são sempre praticados; utilização de workshops em que todos se colocam artisticamente, durante o processo - neste caso, sob a forma de depoimentos - para definir os rumos possíveis da criação etc.), sua configuração remete-nos, entretanto, muito mais ao (recém-nascido e já desgastado) modelo de coletivos artísticos contemporâneos do que, propriamente, de um grupo de teatro.

A começar por seus constituintes: esta equipe (no centro da trajetória estão, permanecendo presentes nas diversas etapas deste pro-

9 Excerto da transcrição da fala de Claudia Schapira no "Encontro de Dramaturgos - Nova Dramaturgia", realizado em 20/07/2005 na Escola Livre de Teatro de Santo André, como parte da Mostra Santo André do Teatro Contemporâneo.

10 Ibidem. 
cesso, além de Schapira, o DJ Eugênio Lima, o grafiteiro Julio Docjsar, a videasta Luaa Gabannini, os atores Roberta Estrela D'Alva, Benito Carmona, Maísa Lepique e Estela Laponi) não é formada apenas por pessoas que se iniciaram, primeira e primordialmente, na prática da linguagem teatral - e nem por sujeitos interessados apenas nisso.

O teatro surge, aqui, como ferramenta para a manifestação do discurso elaborado por artistas plásticos (ou grafiteiros), estilistas (ou recriadores de peças de roupas antigas), dançarinos (ou $B$-boys), $D J s$, músicos, videastas - e também por atores, encenadores e dramaturgos de formação.

Talvez seja por esta razão que a prática teatral do NBD seja, desde os primeiros encontros, uma forma cênica cuja tendência é a fronteira, pouco afeita a espaços convencionais e a modos tradicionais de pensar a cena.

Não por acaso, se o primeiro espetáculo resultante desta reunião de artistas, Bartolomeu - Que será que nele deu?, ainda cabia em um palco italiano em seus diversos formatos assumidos nos espaços em que foi apresentado, o que se vê no decorrer dos anos (e das próximas montagens) é um afastamento progressivo do espaço da tradição até a absoluta dissolução do suporte cênico, em intervenções urbanas para as quais a rua cria a melhor interlocução.

Nesta odisséia ${ }^{11}$ rumo ao presente, são fundamentais os projetos de intervenção urbana, tanto para a definição de um abandono programático das formas cênicas primárias (pu- ras?) como para o nascedouro das teias de ativismo poético que decorrem disso, na rua.

Já em Urgência nas ruas, ${ }^{12}$ invasões inesperadas do espaço da cidade (palco da vida, segundo a dramaturga Claudia Schapira) com propostas provocativas de relação com a paisagem urbana, estimularam um confronto nem sempre formalizável sob a égide do teatro como o conhecemos - justamente na medida em que a participação do transeunte podia redefinir o projeto original e estabelecer um diálogo de natureza performática - plástica, musical, física, ou até mesmo teatral. $\mathrm{O}$ mais importante era, em cada intervenção urbana, instaurar aquilo que Hakim Bey nomeou como Zona Autônoma Temporária (TAZ), 13 festa coletiva em que o poder estabelecido (os costumes, as leis, a polícia, os governantes etc.) está enfraquecido pelo levante de uma situação que não cabe nos padrōes de resposta catalogados.

Assim como a atitude do protagonista Bartolomeu (na verdade, Bartebly, de Herman Melville: "prefere não fazer" o trabalho que lhe é obrigatório graças às convenções) fere frontalmente a norma e deixa exposta a ferida de que tudo silencia diante do incompreensível, também o ativismo poético procura amplificar o caráter transformador das fendas (lacunas, buracos, ilogicidades) deixadas pelo bom funcionamento dos sistemas vigentes.

Casos como a Passeata Amorosa, quando artistas saem às ruas do centro e organizam, com bexigas vermelhas e faixas, um protesto coletivo, mas carregado de um discurso invertido, de

11 O espetáculo Frátria Amada Brasil, atualmente em gestação no NBD, lida com esta mítica grega do reencontro, para tratar justamente do presente do homem brasileiro.

12 Projeto inspirado pela obra de Ned Ludd, Urgência nas ruas, publicada no Brasil na coleção Baderna, da Editora Conrad, de São Paulo.

13 Suas obras TAZ - Zona Autônoma Temporária e Terrorismo poético também foram publicadas no Brasil pela Editora Conrad. Quanto a Bey, pouco se pode afirmar, pois ele próprio se mistura com a mitologia urbana de que trata. Não se conhece sua verdadeira identidade e não há divulgação de seu rosto. Nem sequer podemos afirmar que se trata de um ou de vários autores envolvidos nesta empreitada. 
amor e paz à cidade, com cantos e beijos apaixonados aos desconhecidos que passam, surpreendem o suporte teatral e fazem da cena/ intervenção na rua algo que transborda do conceito tradicional de teatro (de rua).

Como já foi dito, algo mais estranho, cujas matrizes ultrapassam a tradição da comédia popular e que se monta, como nos samplers de um rap, como uma colcha de referências múltiplas e rizomáticas, ${ }^{14}$ típicas de uma cultura popular urbana da contemporaneidade.

O discurso deixa de ser linear e o contato com o espectador (este, às vezes, tão depoente quanto alguém que desdobra seu depoimento conforme os desejos do próprio NBD; há casos em que o microfone chega às mãos dos moradores de rua, que partilham do direito de ter voz ativa: de ser "tudo no seu nome") assume posturas que se aproximam deliberadamente do ativismo poético, deixando em segundo plano a preocupação com uma cena de recorte fabular.

Embora a narrativa seja fundamento do depoimento épico (inspirado pela arejada revisão de Bertolt Brecht), ela também se dissolve em necessidades muito diferentes, pessoais próprias do artista que buscou a performance, desde as últimas décadas do século 20 .

Em algumas provocações de estranhamento, as buscas remetem imediatamente ao terrorismo poético de Hakim Bey, como "uma arma usada para disparar choques estéticos, ao invés de matar". 15

Dançar de forma bizarra durante a noite inteira nos caixas eletrônicos dos bancos. Apre- sentações pirotécnicas não-autorizadas. Landart [corrente que pretende utilizar os espaços naturais como material para a criação artística; para isso fazem coisas como empilhar pedras, traçar imensas linhas de gesso em desertos, cavar tumbas etc.], peças de argila que sugerem estranhos artefatos alienígenas espalhados em parques estaduais. Arrombe apartamentos, mas, em vez de roubar, deixe objetos Poético-Terroristas. Seqüestre alguém \& o faça feliz. ${ }^{16}$

Em Urgência nas ruas, o neo-agitprop se instala como festa, com ares de um "misto manifesto, de teatro invisível, de zona autônoma temporária, de minipeças didáticas e depoimentos": 17

Um carrinho de cachorro-quente, onde se instala um $D J$; placa de achados e perdidos; um microfone onde uma 'locutora' anuncia produtos e faz comentários. Proposto o jogo, as personagens imediatamente reconhecem a sua função. $\mathrm{O}$ homem que passa apressado, pasta debaixo do braço, objetivo certo no olhar, se detém: 'essa música lembra a minha infância [...] gostava de dançar com a minha mãe [...]'. A atriz-locutora aceita o mote, 'deixa' para a contracena e convida o homem para dançar. Dançam na rua. Outros transeuntes param, observam e se colocam, pacto calado, estrategicamente compondo a cena do 'baile'. O DJ assume a figura do locutor dos anos dourados da era do rádio, trazendo à tona mais um importante personagem: fala da guerra, dos que se vão, dos que ficam e, en-

14 Deleuze \& Guattari, 1995.

15 Bey, 2003.

16 Id., ibidem.

17 Schapira, 2004. Trecho extraído do projeto enviado ao Programa Municipal de Fomento ao Teatro do Município de São Paulo, em janeiro de 2004, sob o título "Lendas Urbanas" (projeto não-publicado). Esse projeto, por ter sido contemplado, pode ser consultado na Secretaria Municipal de Cultura da cidade de São Paulo. 
tão, a Estação da Luz, pedra que se comove, disponibiliza seu signo como cenário de uma viagem no tempo, lapso da memória. Aconteceu o teatro? Sinto que $\operatorname{sim} . .{ }^{18}$

Preserva-se o pressuposto teatral, mas o parentesco com o terrorismo poético de Bey é evidente. Assim como trancar atores engravatados dentro da vitrine de uma grande loja de departamentos no centro da cidade e evidenciar, do alto da arrogância capitalista das personagens criadas, o asco pelos passantes, enquanto um DJ fala diretamente aos transeuntes-espectadores, faz do espaço da cidade um campo para o estranhamento.

Nos demais projetos de intervenção, tanto Lendas urbanas quanto as duas Vigílias culturais organizadas em regióes centrais da cidade (sob o Minhocão e na Praça do Patriarca, em memória dos moradores de rua brutalmente assassinados naquelas redondezas), a dissolução do espaço mantém-se evidente e vai ecoar na construção dos demais espetáculos, em que as matrizes cênicas são, enfim, mais amadurecidas.

A organização (e utilização) do espaço em Acordei que sonhava, sampler feito à base do teatro barroco do Século de Ouro Espanhol, na língua finamente métrica e musical de Calderón de La Barca, já apontava para os rumos deste vetor.

O público, disposto em arquibancadas que formam (junto com aparelhos de TV que assumem a condução de parte dos significados da cena, em tempo real) uma mandala, está dentro da cena - em disposição épica de ruptura com qualquer possível ilusionismo. No terceiro passo desta caminhada, Frátria Amada Brasil também não cabe em uma única perspectiva do olhar. As cenas, embebidas pelo vigor do happening e pelo jogo processional com a platéia, articulam-se sobre um tabuleiro que reproduz a Árvore da Vida da Cabala judaica.
Ou seja, apresentaram-se até aqui alguns dos pilares e arcobotantes que mantêm de pé esta catedral gótica, arquitetada por contradições explícitas e que, exatamente por isso, toca tão profundamente o olhar ambíguo do seu espectador, este homem enraizado no presente: 1 . o diálogo entre o teatro e o hip-hop traz até a cena procedimentos que contaminam os recursos e os potencializam com ritmo e poesia (rap), dança (de rua, street dance), samplers (que organizam sobreposiçōes francamente rizomáticas no discurso) e outros motores visuais (como o grafitte e a vídeo-arte); 2. o depoimento como forma de extração da atitude artística do criador, amplificando sua relação ética e seu compromisso pessoal com a malha discursiva recortada, fragmentária e plural que forma o espetáculo ou a intervenção; 3. a construção coletiva e colaborativa dos projetos e dos aspectos cênicos selecionados; 4. a multiplicidade extremamente contemporânea de referências vindas de diversas linguagens que se acumulam e se transformam, no processo de construção de cenas e intervenções; 5 . a inspiração brechtiana de um teatro épico desbragado, relido em sua dimensão menos ortodoxa e propositora não somente de problemas, mas de saídas para o beco da realidade social em crise em que se manejam os tópicos da criação; 6. a interação com textos teóricos que pensam sobre a arte como se ela alcançasse o poder de uma máquina transformadora, pelo viés de um neo-anarquismo que pretende demolir as carcaças das instituições burguesas menos evidentes - tratamos aqui do terrorismo poético e do TAZ (Zona Autônoma Temporária), de Hakim Bey, e dos Reclaim of Streets, descritos por Ned Ludd, em Urgência nas ruas; 7. a presença de uma crença espiritual que recupera sentidos primordiais para o território sagrado da criação - daí ressoam os interesses pela mitologia e pelas práticas xamânicas, que bradam em cantos de louvor a um novo tempo, a uma nova era.

18 Id., ibidem. 
Assim, a amplificação do conceito de dramaturgia começa a ser enredada. Menos conflito do que trama, esta "dramaturgia expandida" faz-se como uma rede de entrelaçamentos de recursos cênicos textuais e não-verbais, mais sobreposição sampleada de diferentes tessituras que compõem o rito urbano da cena.

Aspectos renovadores de padrões formais, no campo da dramaturgia, tais como o jogo com a imprevisibilidade (que é o lance de dados do tempo presente, especialmente nas intervenções urbanas, mas na poética da rua, como um todo), a ruptura com as delimitações convencionais de tempo-espaço, o uso da música e a fusão de linguagens, a abertura para a dimensão da utopia, a pluralidade simultânea de referências, a sobreposição de procedimentos imaginativos (a imagem como texto espetacular) e narrativos, a polissemia, a polifonia, a quebra de linearidades, a emersão do discurso poético épico, o caráter coletivo da criação e a sacralização da ação cênica, indicam posturas que se avizinham à formalização do que, no xamanismo, nomeia-se como transe - linguagem de contato com as divindades, interdita a não-iniciados.

Entretanto, camadas de leitura se abrem, distintas. Aos iniciados (ou identificados com o projeto do NBD), cabe a compreensão de nuances e detalhes, por signos que instauram leituras paralelas às que dão um fundamento mínimo para a cena.

Aos menos afeitos à linguagem simbólica do transe, situações solidamente instauradas conduzem o espectador a estados satisfatórios de crítica às contradições do tempo presente, pelo viés da narrativa atualizada, como em Brecht: se para Calderón de La Barca, séculos atrás, a opção de Segismundo pela tirania e pelo absolutismo resultava da vocação poética do autor espanhol para espelhar e antever os rumos da história, em Acordei que sonhava (espetáculo imaginado em um país arrasado pelo absolutismo racista e escravocrata de sua colonização exploratória, em que a tirania construiu os horrores de uma exclusão descarada, que ainda hoje trafega pelas ruas, como se fossem naturais a miséria e a desinformação - privaçōes de um novo Segismundo) é preciso refazer com novos sonhos a utopia. E, com novas escolhas, re-arranjar a poesia.

Disforme em relação aos modelos da tradição, customizada e não-linear, imagética e rizomática, esta dramaturgia que é, portanto, teia (trama, e não conflito) reúne as características do projeto xamânico que a ladeia: ela é o canto e seu propósito é o encanto.

Deste encantamento nascerá o futuro:

Toda obra de arte é filha de seu tempo e, muitas vezes, mãe dos nossos sentimentos. ${ }^{19}$

Se cada época cria uma arte que lhe é própria e que jamais se verá renascer (este é o princípio em que crê este xamanismo), o encantamento se dá pela articulação do que é espiritual na arte. O formalismo sagrado e as forças xamânicas atribuídas à palavra, assim como todas as demais gramáticas da criação, constroem um jogo abstrato (geométrico, às vezes, como uma mandala; dotado de sentidos secretos, noutros, como a fala da Cabala; caótico, quando os fluxos vêm das leis do acaso, na rua) de sentidos em que o desejo é comunicar o incomunicável. Pistas são acumuladas no caminho utópico proposto ao Deus Mercúrio, e o melhor leitor é aquele que não tem medo de assumir a faceta de um cão farejador, regido pelas hostes de Diana caçadora.

As respostas puramente materiais não são vistas como suficientes para a construção do futuro. Assim como em Kandinsky (texto de cabeceira de Claudia Schapira), acredita-se que "após um longo período de materialismo de que

19 Kandinsky, 2000. 
está apenas despertando, nossa alma acha-se repleta de germes de desespero e de incredulidade, prestes a soçobrar no nada". ${ }^{20} \mathrm{~A}$ alma - justamente na medida em que só se compreende o sujeito-homem em uma tríade de corpo-menteespírito - "se pergunta se a luz não será o sonho, e a escuridão a realidade". ${ }^{21} \mathrm{Na}$ montagem de Acordei que sonhava, esta pista está sublinhada.

Também é pela prática xamânica (espiritual) que retornamos à multiplicidade que se casa perfeitamente com o hip-hop. Pelo viés espiritual é que, por exemplo, a dramaturgia de Claudia Schapira abre espaço para que sua construção teatral potencialize tanto a contaminação entre os diferentes elementos como também a convivência de diversas linguagens, em um fenômeno que aceita o cruzamento de múltiplas referências.

Quando eu falei que eu considero a dramaturgia a somatória dos elementos, o que eu quero dizer é que eu não consigo compreender um teatro desvinculado do movimento, por exemplo. Eu entendo quando se diz que o movimento está mais em evidência, como se estivéssemos fazendo um zoom neste elemento. Quando a Pina Bausch começou, décadas atrás, com a dança-teatro, buscando o atrito entre estas linguagens, ela começou a 'dramaturgizar' a dança, no sentido de roteirizar. Já começou a haver um casamento disso. Mas eu tenho um texto que eu gosto muito, que se chama $O$ primeiro dramaturgo, que fala sobre o primeiro dramaturgo como um coreógrafo, porque antes de nascer a palavra, a primeira partitura era completamente gestual. Os primeiros registros que se têm do que poderia vir a ser o teatro, é movimento no espaço: rito. Do sagrado, a trajetória nos leva ao profano e vira arte: vem do movimen- to... Então, essa idéia de uma dramaturgia como somatória dos elementos é um resgate que vem num momento em que a necessidade de sacralizar a vida e de operar a retomada do rito está muito presente. Eu acho muito propício que esteja acontecendo esta retomada. Porque é através do corpo, o mais concreto do que nós temos (já que enquanto espiritualidade tudo é muito impalpável), que podemos materializar o inexprimível. Eu leio nisso a retomada da necessidade da arte como rito. É claro que ela nunca perdeu essa função, que nasceu disso, mas às vezes esquecemos esta entre outras coisas. É um religare. ${ }^{22}$

Desta forma, a linguagem advinda do movimento hip-hop (que é, por natureza, multifacetada e plural) mostra-se adequada para a constituição desta teatralidade, pois reúne poesia, música (rap, dj etc.), dança (street dance), manifestações plásticas (grafite, pichações), e especialmente uma proposta ética muito específica, favorável ao que é periférico e marginal - e que subverterá para o surgimento do que é "novo".

A capacidade de comunicação da cultura hip-hop, na contracena com o homem contemporâneo, é que produz, finalmente, a possibilidade de um rito com comunhão:

O grande risco que a gente vê acontecer com os defensores da ritualização é a construção de ritos sem comunhão. E o rito só tem sentido no teatro quando se faz com a platéia um trabalho comunhão. E nisso eu volto a notar a importância da comunicação, especialmente quando se fala da abstração do movimento e do corpo. A arte procura sempre falar do que não tem como ser dito. $\mathrm{Na}$ arte, tudo é abstrato, mas ao mesmo tempo tudo é possível. Um gesto no espaço pode ter diver-

20 Id., ibidem.

21 Id., ibidem.

22 "Encontro de dramaturgos - Nova dramaturgia", na ELT, em 2005. 
sos significados e depende do contexto em que ele se apresenta. Depende da maneira como você vai condensar as informaçóes. ${ }^{23}$

As conexões entre a prática multimidiática do teatro-hip-hop e os "aprendizados" extraídos dos estudos baseados nas práticas de xamanismo são os pontos, aliados à prática do teatro épico (que permite o uso do depoimento artístico objetivo), que definem a poética do NBD.

Quanto à qualidade múltipla do teatrohip-hop, não restam dúvidas. Claudia Schapira declarou, em um de seus manifestos, que:

Quando demos início à pesquisa do projeto Urgência nas ruas, estávamos, lado a lado, estreando o espetáculo Acordei que sonhava (livre adaptação de $A$ vida é sonho, de Calderón de La Barca) e, portanto, começando a vislumbrar os primeiros resultados do 'passo a mais' proposto por este espetáculo em relação à pesquisa inicial do núcleo (o espetáculo Bartolomeu, Que Será Que Nele Deu?, primeiro trabalho do grupo), que pressupunha o diálogo entre a cultura hip-hop e o teatro épico.

'Passo a mais' que propunha agora ir além da contracena de elementos, mas que buscava sua fusão, configurando um 'novo elemento', um 'fruto-linguagem' próprio e específico, que nós apelidamos carinhosamente de teatro-hip-hop.

E, no decorrer da temporada, que apontou, entre erros e acertos, um resultado extremamente positivo, começamos a nossa peregrinação urbana do projeto Urgência nas ruas. As intervenções beberam de imediato nos [...] pequenos avanços que essa busca de linguagem começava a despontar no espetáculo Acordei que sonhava:
- atores-MCs, usando a palavra como instrumento de auto-representação, cada vez mais conscientes dessa atitude cênica, e então propondo formas de interação distintas na relação com a rua;

- a diversificação da cena, agora incorporando os elementos da cultura hip-hop como personagem e conceito (como a $D J$ do espetáculo, que interpreta a personagem Rosaura, utilizando a imagem libertária do dj como paralelo e discurso para a concepção da personagem; ou o rap usado como verbo da personagem Segismundo, concebida a partir da observação dos jovens 'confinados' na periferia) e a partir daí, ampliar as possibilidades da criação de personagens e de situações na rua, já que poderíamos, por exemplo, usar a pickup como porta-voz do discurso ou um ator como elemento cênico, experimentando as variantes das funçôes dos elementos da cena; - a utilização do graffite como representante da arte das ruas de forma mais abrangente, como um conceito, como paisagem-moldura do espaço cênico;

- a dança de rua pontuando como linguagem, ao longo do espetáculo, o repertório gestual dos artistas na cena;

- a narrativa sendo conduzida por vários recursos cênicos e não necessariamente pelo texto ou pela ação, mas através da música ou de imagens, por exemplo. ${ }^{24}$

Esta síntese apontada por Schapira revela o teor de deslocamento ${ }^{25}$ da forma teatral para um território instável, de experimentação formal. A superação das normas da dramaturgia tradicional cria aberturas para que surja um diálogo ágil com as deformações (invenções, aspectos incomuns) da linguagem cênica.

\section{Ibidem.}

24 Schapira, 2004.

25 Barthes, 1978. 
É assim que, no NBD, o hip-hop é tratado como uma licença poética. Para além da atitude e da ética (ou da mera reprodução de princípios estéticos - já que nem sempre a forma do rap pode ser lida objetivamente, na cena), o material se estabelece de fato, como um conjunto de princípios criativos organizacionais do imaginário e da prática diária de ensaios - como referencial para o treinamento de um tipo específico de ator (ator-MC), em que a forma crucial de expressão é o depoimento.

Com o rap, esse ator prepara um corpo próprio - treinado não só poética, mas corpo- ral e ritmicamente. As artes visuais da rua evidenciam para o olhar quais são as preocupações que estão em jogo: visibilidade e identidade.

Nas mesmas condiçóes dos grandes projetos de encenação do século 20 , em que um ator buscava um treinamento corpóreo, vocal e conceitual rigoroso, dotado de unidade, para responder ao projeto estético de um encenador, aqui é a cultura de rua que se projeta como matriz de proposiçôes para um novo teatro. E, nesse novo teatro nascido das ruas, é possível cantar, dançar e trabalhar com narrativas cênicas usando nos pés um tênis All Star vermelho.

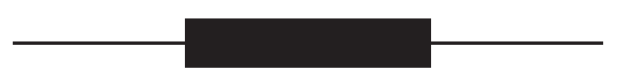

\section{Referências bibliográficas}

ALVES, César. Pergunte a quem conhece: Thaíde. São Paulo: Labortexto Editorial, 2004.

BARTHES, Roland. Aula. São Paulo: Cultrix, 1978.

BEY, Hakim. TAZ - Zona Autônoma Temporária. São Paulo: Conrad, 2001. CAOS - Terrorismo poético e outros crimes exemplares. São Paulo: Conrad, 2003.

COHEN, Renato. A performance como linguagem. São Paulo: Perspectiva, 1989.

DELEUZE, Gilles \& GUATTARI, Félix. Mil platôs - Capitalismo e esquizofrenia. Rio de Janeiro: Editora 34, 1995.

ECO, Umberto. A obra aberta. São Paulo: Perspectiva, 1968.

FARIAS, Agnaldo. Arte brasileira hoje. São Paulo: Publifolha, 2002.

FIORIN, José Luiz. Linguagem e ideologia. São Paulo: Ática, 1997.

KANDINSKY, Wassily. Do espiritual na arte. São Paulo: Martins Fontes, 2000.

KEHL, Maria Rita. Da lama ao caos: a invasão da privacidade na música do grupo Nação Zumbi. In: CAVALCANTI, Berenice; STARLING, Heloisa \& EISENBERG, José. Decantando a república - Inventário histórico e político da canção popular moderna brasileira. Vol. 3: A cidade não mora mais em mim. Rio de Janeiro: Nova Fronteira/Fundação Perseu Abramo/FAPERJ, 2004. 
LÉVY, Pierre. A revolução contemporânea em matéria de comunicação. In: MARTINS, Francisco M. \& SILVA, Juremir M. (orgs.). Para navegar no século XXI. Tecnologias do imaginário e cibercultura. Porto Alegre: Sulina/Edipucrs, 1999, p. 195-216.

LUDD, Ned. (org.). Urgência nas ruas - Black block, reclaim the streets e os dias de ação global. São Paulo: Conrad, 2002.

SCHAPIRA, Claudia. Bartolomeu, que será que nele deu? In: Coleção Dramaturgia. São Paulo: CCSP, 2004.

. Lendas Urbanas. Projeto não publicado.

"Teatro de rua, teatro na rua, teatro da rua, teatro para a rua, teatro com a rua?". Cadernos da ELT, Ano 2, Número 1. Santo André: Escola Livre de Teatro, 2004.

SOARES, Luiz Eduardo. Uma questão de atitude: O Rappa e as novas formas de intervenção política nas cidades brasileiras. In: CAVALCANTI, Berenice; STARLING, Heloisa \& EISENBERG, José. Decantando a república - Inventário histórico e politico da canção popular moderna brasileira. Vol. 3: A cidade não mora mais em mim. Rio de Janeiro: Nova Fronteira/Fundação Perseu Abramo/FAPERJ, 2004.

SOARES, Luiz Eduardo, BILL, MV e ATHAYDE, Celso. Cabeça de porco. Rio de Janeiro: Objetiva, 2005. 